\title{
ALGUNOS TOPÓNIMOS INDÍGENAS DE LA PROVINCIA DE PUNTARENAS, COSTA RICA
}

\author{
Flor Garita Hernández
}

\begin{abstract}
RESUMEN
Se seleccionó un corpus de 94 vocablos indígenas que dan nombre a ríos, quebradas, cerros, filas y poblados, pertenecientes a las etnias que aún conservan hablantes, con el fin de establecer la lengua a que pertenecen y determinar los significados de las raíces que constituyen las palabras. Del corpus, mediante el trabajo de campo, se lograron analizar 81 vocablos y se adjunta una lista de nombres pendientes que los informantes no lograron identificar con exactitud, para futuras investigaciones. Del estudio realizado se concluye que, al igual que en los topónimos que se han analizado en lengua española, los nombre indígenas reflejan la interacción del hombre con el medio; por tanto, los nombres seleccionados corresponden a elementos del medio tales como fauna, flora y objetos y sustancias minerales.
\end{abstract}

\begin{abstract}
A corpus of 94 Indian terms used by ethnic groups that still have native speakers of the languages and that name rivers, creeks, hills, ranges and villages was selected to define the language of each term and the meanings of the word roots. Fieldwork enabled the analysis of 81 terms in the corpus. A list of names that the informants were not able to identify exactly is included as a source for future research. The findings reveal that, like the Spanish toponyms analyzed and reported elsewhere, Indian names indicate the way people and nature interact. Thereforee, those identified refer to elemnts in the environment, such as the fauna and flora, objects and minerals.
\end{abstract}

\section{Introducción}

Puntarenas es la provincia más grande de Costa Rica, con una superificie de $11265,69 \mathrm{Km}^{2}$, que corresponde al 22,5\% del territorio nacional. Se extiende desde la parte sur de la Península de Nicoya hasta la frontera con Panamá. Esta situación ha permitido que en su nomenclatura geográfica se encuentren vocablos de casi todas las lenguas indígenas que se hablaron y que se hablan hoy en nuestro país, aparte de todos los nombres indígenas traídos por los españoles de otras regiones de América. En esta investigación se trabajó únicamente con nombres 
pertenecientes a las etnias cuya lengua aún se habla y que se pudieron averiguar in situ. Estos grupos son los bribris, hablantes de bribri; los cabécares, hablantes de cabécar y los borucas, hablantes de boruca. Los vocablos correspondientes a los térrabas, de los que, como se sabe, solo quedan tres hablantes, no se han podido investigar. Solo se tiene certeza de tres vocablos, gracias a la colaboración del Dr. Adolfo Constenla, quien está trabajando a fondo con la reconstrucción de esta lengua. Tampoco se tiene certeza de topónimos de origen guaimí.

En el presente trabajo se seleccionó un corpus de 94 vocablos correspondientes a hidrónimos: nombres de ríos y quebradas; orónimos: nombres de cerros, filas, sabanas; y ecónimos: nombres de poblados, con el fin de establecer la lengua de la cual provienen y las raíces con su respectivo significado. Respecto de este último objetivo, se logró analizar un total de 81 vocablos, aunque en unos tres casos los informantes no pudieron identificar con exactitud los significados de todas las raíces que componen la palabra. El corpus se levantó de las hojas cartográficas de Buenos Aires, Burica, Cabagra, Coto Brus, Chánguena, Dominical, Durica, General, Kamuk, Llorona, Pittier y Unión, elaboradas por el Instituto Geográfico Nacional. La información se obtuvo mediante el trabajo de campo, entrevistas realizadas a los indígenas en las distintas comunidades indígenas de la provincia de Puntarenas, además de otras entrevistas que se hicieron a informantes indígenas residentes en la provincia de San José, cuyos nombres aparecen al final de esta investigación, bajo el título de Informantes. También se incluye al final, como anexo, una lista de topónimos que con seguridad son de origen indígena pero que, muchos de ellos, ya los informantes no los reconocen por haberse distorsionado su pronunciación. Esto se debe a que, cuando se levantaron las hojas cartográficas, no se supo o no se entendió el nombre que el indígena le daba al accidente geográfico y se perdió toda esa riqueza linguística de vocablos que ya no tienen significado ni para los hablantes de español ni para los mismos indígenas. También pudo ser que la variante venía ya desde antiguo.

\section{El corpus}

El corpus se ha organizado de la siguiente manera: el Topónimo, que corresponde al nombre del accidente o del poblado; la Característica, que indica qué tipo de accidente es (por ejemplo, río, quebrada, sabana, fila, etc.); bajo el rubro Lengua se ubica el nombre como perteneciente a una lengua indígena determinada; el Mapa Básico corresponde al nombre de la hoja cartográfica donde se registra el accidente o poblado y, finalmente, las Coordenadas geográficas, que permiten localizar el nombre desde el punto de vista geográfico.

A continuación la ubicación respectiva.

$\begin{array}{lllll}\text { Topónimo } & \text { Característica } & \text { Lengua } & \text { Mapa Básico } & \text { Coorden. } \\ & & & & \\ \text { Akum } & \text { Río } & \text { Bribri } & \text { Kamuk } & 547352 \\ \text { Ambrí } & \text { Río } & \text { Bribri } & \text { Cabagra } & 553345 \\ \text { Ambruí } & \text { Cerro } & \text { Bribri } & \text { Kamuk } & 553348 \\ \text { Amú } & \text { Cerro } & \text { Bribri } & \text { Durica } & 542366 \\ \text { Amúo } & \text { Cerro } & \text { Bribri } & \text { Cabagra } & 562341 \\ \text { Amurical } & \text { Quebrada } & \text { Bribri } & \text { General } & 542345\end{array}$




\begin{tabular}{|c|c|c|c|c|}
\hline Topónimo & Característica & Lengua & Mapa Básico & Coorden \\
\hline Ajcokichadik & Quebrada & Bribri & Buenos Aires & 544350 \\
\hline Apó & Cerro & Bribri & Cabagra & 571340 \\
\hline Araki & Cerro & Bribri & Cabagra & 563345 \\
\hline Arara & Cerro & Bribri & Kamuk & 555350 \\
\hline Ayatimba & Quebrada & Bribri & General & 537336 \\
\hline Bekri & Cerro & Bribri & Kamuk & 555350 \\
\hline Beri & Cerro & Bribri & Cabagra & 564346 \\
\hline Bita & Cerro & Bribri & Kamuk & 553355 \\
\hline Blorikal & Río & Bribri & Buenos Aires & 540347 \\
\hline Blorikal & Río & Bribri & General & 540344 \\
\hline Boruca & Poblado & Boruca & General & 538328 \\
\hline Boruca & Quebrada & Boruca & General & 527336 \\
\hline Boruca & Quebrada & Boruca & Chánguena & 539327 \\
\hline Boruca & Quebrada & Boruca & Quepos & 458378 \\
\hline Bruncri & Quebrada & Boruca & General & 537329 \\
\hline Bruran & Sabana & Boruca & General & 540333 \\
\hline Bukí & Quebrada & Bribri & Pittier & 584332 \\
\hline Bunú & Quebrada & Bribri & Pittier & 581332 \\
\hline Burí & Quebrada & Bribri & Unión & 591327 \\
\hline Cabagra & Fila & Cabécar & Pittier & 549342 \\
\hline Cabagra & Poblado & Cabécar & Cabagra & 550334 \\
\hline Cabagra & Río & Cabécar & Cabagra & 549343 \\
\hline Canchén & Quebrada & Boruca & Chánguena & 535321 \\
\hline Canchén & Cerro & Boruca & Chánguena & 536320 \\
\hline Cansot & Poblado & Boruca & Chánguena & 525324 \\
\hline Cansot & Quebrada & Boruca & Chánguena & 526323 \\
\hline Carse & Laguna & Térraba & General & 535336 \\
\hline Castán & Fila & Boruca & General & 534330 \\
\hline Chamba & Quebrada & Boruca & General & 534331 \\
\hline Chin Beta & Fila & Bribri & Cabagra & 557345 \\
\hline Chmuri & Quebrada & Bribri & Buenos Aires & 543350 \\
\hline Chubugra & Río & Bribri & Buenos Aires & 543361 \\
\hline Coobó & Quebrada & Boruca & Chánguena & 537321 \\
\hline Coobó & Fila & Boruca & Chánguena & 538320 \\
\hline Cramancragua & Sabanas & Boruca & General & 535335 \\
\hline Cuabrí & Cerro & Bribri & Kamuk & 552351 \\
\hline Cuabrí & Río & Bribri & Kamuk & 552351 \\
\hline Cuasrán & Cerro & Boruca & Chánguena & 536324 \\
\hline Cuij Cuij & Sabana & Boruca & Chánguena & 538326 \\
\hline Datsi & Cerro & Bribri & Kamuk & 559354 \\
\hline Deuí & Río & Bribri & Kamuk & 557348 \\
\hline Dibul & Cerro & Bribri & Cabagra & 568344 \\
\hline Ditsirí & Quebrada & Cabécar & Buenos Aires & 540358 \\
\hline
\end{tabular}




\begin{tabular}{|c|c|c|c|c|}
\hline Topónimo & Característica & Lengua & Mapa Básico & Coorden \\
\hline Ditsirí Suk & Sabana & Bribri & Buenos Aires & 540357 \\
\hline Declarí & Río & Cabécar & Buenos Aires & 540361 \\
\hline Dlora & Quebrada & Bribri & Buenos Aires & 543357 \\
\hline Dobóncragua & Poblado & Térraba & General & 538334 \\
\hline Dobondecito & Quebrada & Térraba & Buenos Aires & 536350 \\
\hline Dobonde & Quebrada & Térraba & Buenos Aires & 536351 \\
\hline Durega & Quebrada & Cabécar & Buenos Aires & 541363 \\
\hline Guai & Quebrada & Bribri & Cabagra & 553334 \\
\hline Hurrí & Quebrada & Bribri & Coto Brus & 572231 \\
\hline Jakbarari & Quebrada & Cabécar & Buenos Aires & 541360 \\
\hline Jakyaka & Sabana & Bribri & Buenos Aires & 541362 \\
\hline Kaí & Cerro & Bribri & Kamuk & 549359 \\
\hline Kebé & Cerro & Bribri & Cabagra & 565344 \\
\hline Kitorí & Quebrada & Cabécar & Buenos Aires & 540354 \\
\hline Korí & Quebrada & Cabécar & Buenos Aires & 540355 \\
\hline Koronono & Quebrada & Cabécar & Buenos Aires & 543356 \\
\hline Kuákua & Cerro & Bribri & Cabagra & 566344 \\
\hline Kuiyé & Río & Cabécar & Buenos Aires & 542357 \\
\hline Mirur Bisuk & Sabana & Bribri & Buenos Aires & 541363 \\
\hline Nai & Cerro & Bribri & Kamuk & 565352 \\
\hline Oka & Sabana & Bribri & Buenos Aires & 543362 \\
\hline Pirgú Krikú & Quebrada & Cabécar & Buenos Aires & 541354 \\
\hline Ruchen & Fila & Boruca & General & 532330 \\
\hline Ruchen & Río & Boruca & General & 532330 \\
\hline Sankraua & Fila & Boruca & Coto Brus & 547311 \\
\hline Sarai & Río & Cabécar & Buenos Aires & 536359 \\
\hline Sebror & Quebrada & Bribri & Buenos Aires & 539347 \\
\hline Sebror & Sabana & Bribri & Buenos Aires & 538349 \\
\hline Simar & Quebrada & Bribri & Coto Brus & 572319 \\
\hline Sinancra & Finca & Boruca & Chánguena & 532326 \\
\hline Sipar & Fila & Bribri & Kamuk & 547353 \\
\hline Sipar & Río & Bribri & Kamuk & 547353 \\
\hline Sipardia & Quebrada & Bribri & Buenos Aires & 545352 \\
\hline Skrá & Río & Cabécar & Buenos Aires & 537360 \\
\hline Suidiñario & Quebrada & Bribri & Buenos Aires & 540350 \\
\hline Surá & Río & Bribri & Unión & 598326 \\
\hline Tirgrá & Quebrada & Cabécar & Buenos Aires & 542356 \\
\hline Uíkuro & Cerro & Bribri & Cabagra & 570340 \\
\hline Uká & Cerro & Bribri & Cabagra & 569343 \\
\hline Ururí & Quebrada & Cabécar & Buenos Aires & 539355 \\
\hline Yheri & Quebrada & Bribri & Buenos Aires & 542350 \\
\hline Yimba & Río & Boruca & General & 540329 \\
\hline Yurá & Quebrada & Bribri & Buenos Aires & 545353 \\
\hline
\end{tabular}




\section{Las comunidades indígenas y sus lenguas}

En la provincia de Puntarenas existen cinco culturas indígenas con vitalidad todavía: la etnia boruca se ubica en diversas comunidades como Boruca, Chánguena, Lagarto, Bijagual y Currés; de ellas las principales son Boruca y Currés, pero todas están situadas en la reserva Boruca. Su lengua es la boruca. Según Bozzoli (1973), los borucas se parecen mucho en sus costumbres a los campesinos no indígenas de esa zona y sus rasgos autóctonos se mantienen en forma muy limitada: aún hay viviendas con techo de zacate de sabana, se usan guacales y se hila el algodón. Los borucas han sabido modernizarse y al mismo tiempo mantener su identidad. Constenla (1986) explica que la cultura boruca es mestiza, rasgo que se advierte en sus narraciones, pues se da una coexistencia de prácticas indígenas con costumbres hispánicas. Esta situación es muy patente en el campo de las concepciones religiosas: aunque profesan el catolicismo, sus creencias indígenas están muy arraigadas y vinculadas a las creencias de los pueblos de América del Sur, en particular de la región atlántica. Celedina Maroto Leiva (1998) manifiesta que de su cultura, la boruca, solo quedan la artesanía, principalmente en algodón teñido de diversos colores con tintas sacadas de vegetales, las comidas y algunas actividades festivas, como la fiesta de los diablitos (Cfr. Rojas 1998). Respecto de la población, en Boruca viven unos 1200 indígenas y en Curré unos 600.

La etnia cabécar se ubica hacia el centro del país por las vertientes del Atlántico y del Pacífico. Son hablantes de cabécar. Un grupo de ellos vive en Ujarrás y China Kichá, en Buenos Aires y Pérez Zeledón respectivamente. Según Bozzoli, los cabécares pueden ser 1500 aproximadamente.

La etnia bribri, por el lado del Pacífico, ocupa la reserva de Salitre y Cabagra y tiene como lengua nativa el bribri. Es el grupo más numeroso: suman entre unos 3000 a 4000 en total. Los bribris se mezclan con los cabécares y ambos forman el grupo talamanqueño. Tanto los cabécares como los bribris son muy parecidos en sus rasgos culturales: ambos tienen sukias o curanderos que atienden ciertas enfermedades y se encargan de las ceremonias del nacimiento y de la muerte. Además, ambos grupos se dedican a las actividades agrícolas. Los cabécares se ubican en Ujarrás con aproximadamente 1800 habitantes, todos hablantes de cabécar.

En cuanto a su cultura, según nos informó el indígena Silvano Villanueva, todavía mantienen las costumbres de su etnia, aunque ahora no tienen curandero porque se murió. La mayor parte de sus casas son de madera o caña con techo de zacate llamado "suk" en cabécar. La alimentación básica es con banano, verduras, además de gallina y chompipe de vez en cuando. Ya no cazan porque no hay animales, todos han desaparecido. Cultivan yuca, chayote, ayote y plátano; de la producción, toman para su sustento y venden el excedente.

Los problemas de salud los atiende un médico que envía la Caja Costarricense de Seguro Social cada mes y les lleva medicinas. Si tienen emergencias llaman a la ambulancia de Buenos Aires por medio del teléfono público que existe en la localidad. Además cuentan con una escuela bilingüe en la que aprenden el español y el cabécar. Actualmente, el problema que los afecta son los bajos salarios que devengan en las fincas agrícolas y ganaderas para las que trabajan, las cuales les pagan quinientos colones por jornal (al día) con lo que mantienen familias con un promedio de ocho o nueve niños por pareja.

La etnia térraba, dispersa en la reserva Boruca-Térraba, también en Buenos Aires, conserva únicamente tres hablantes de su lengua térraba que se ha diferenciado mucho del 
teribe que se habla en Panamá por el Atlántico. Finalmente, en el distrito de Limoncito del cantón de Coto Brus y en Abrojos, cerca de Villa Neilly, Montezuma y Conte Burica, se encuentra ubicada la etnia guaimí. Los guaimíes han estado cruzando la frontera desde Chiriquí en las últimas décadas. Son hablantes de la lengua guaimí más que de la española. Entre sus actividades combinan la agricultura con la cacería y la pesca.

Según Bozzoli, el indígena costarricense ha sido agricultor parcial; ha dependido tanto de los cultivos como de la caza, de la pesca y de la recolección de productos silvestres. El sistema actual rural costarricense va eliminando la explotación de lo silvestre y obligando al indígena a depender de sus cultivos y de los animales que pueda criar (el cerdo es el animal doméstico que más contribuye a la alimentación seguido en importancia por las gallinas, la fauna de los ríos y animales de monte).

Desde el punto de vista legal, gran parte de los indígenas se encuentra en reservas que constituyen un tipo de comunidad colectiva o comunitaria. La Comisión Nacional Indígena, CONAI, es la que se encarga de velar por los intereses de acuerdo con lo estipulado en las leyes 5221, Ley de creación de la comisión nacional de asuntos indígenas, y 6172, Ley indígena. La población de cada una de las reservas constituye una sola comunidad administrada por un Consejo Directivo, representante de toda la población. Actualmente funciona una asociación denominada Aradikés, constituida por indígenas que ayudan a sus comunidades.

En lo relativo a las lenguas y de acuerdo con Constenla (1986), todas lenguas habladas por estas comunidades pertenecen a la familia sudamericana chibcha. Respecto del boruca, según datos suministrados por Celedina Maroto, indígena y maestra de lengua boruca en Curré, actualmente solo quedan dos ancianas que hablan perfectamente la lengua; esas personas son sus dos abuelas: las señoras Paulina Leiva y Rafaela Maroto; además, hay unos cinco que hablan bastante bien y unas cuatro personas que recuerdan palabras. Como maestra de lengua materna en su comunidad, doña Celestina carece de las condiciones mínimas para la enseñanza del boruca, pues ni siquiera tiene una grabadora para que sus estudiantes puedan escuchar las narraciones en su propia lengua o bien hacer prácticas de pronunciación y autoescucha. Quesada Pacheco (1996) expone que en la villa Boruca junto con Curré se concentra una población indígena con un número aproximado de 2000 habitantes. En el distrito de Boruca solamente siete personas hablan el idioma boruca como lengua materna o fluidamente. Unas cuantas personas entre 40 y 80 años son semihablantes: entienden la lengua pero tienen grandes dificultades al hablarla. Los jóvenes y los niños dominan algunas palabras pero no son capaces de comprenderla del todo. Este autor concluye que el boruca es hoy una lengua declinante.

La toponimia indígena de estas etnias es un tema que debe estudiarse con muchos informantes y con un investigador que conozca a fondo las lenguas mencionadas; no obstante, como una primera aproximación, se ofrece este estudio que es parte de la investigación Toponimia de la provincia de Puntarenas, con el fin de motivar futuras investigaciones de los interesados en temas indígenas.

Para realizar el estudio se han tenido presentes algunos criterios expuestos por Corominas (1972) respecto de la investigación de topónimos de origen indígena. De acuerdo con este autor, si se atienden estos criterios se puede llegar a conclusiones algo seguras aunque no tan explícitas respecto de la etimología. Por otra parte, muchos de estos nombres se han castellanizado; es decir, además de haber sido adaptados a la fonética del español, se han hecho derivaciones con sufijos españoles, tal es el caso del topónimo Dobondecito, quebrada a cuya 
raíz "dobó"n 'tigre' dí 'agua' se le agregó el diminutivo español -cito, para formar el nombre Dobondecito.

Entre los criterios que señala Corominas están:

"Área geográfica": no deben buscarse lenguas indígenas donde no hubo indios hablantes de esas lenguas. En nuestro caso, los hablantes están en esa región.

"Terminaciones características": en todos los países hay terminaciones típicas de una zona que caracterizan su paisaje toponímico. En el caso que nos ocupa, estas terminaciones forman parte de la estructura de su respectiva lengua; por ejemplo, la terminación rí 'agua', tanto en la lengua cabécar como en la bribri.

"Las leyes gramaticales": se debe conocer la estructura de la lengua de origen del topónimo para no caer en error. Esta es la razón por la que se indicó al inicio que un trabajo profundo requiere del conocimiento también profundo de cada lengua.

"La fonética histórica": para sentar sólidamente una etimología es indispensable que las diferencias fonéticas entre la forma actual y la que suponemos fuese forma originaria, se ajusten rigurosamente a las normas de la fonética histórica.

"Fonemas característicos": puede bastar la presencia de cierto fonema o combinación fonética para orientar nuestras indagaciones hacia determinada lengua o grupo de lenguas.

"Comparación semántica": es importante comparar topónimos aunque sean de distintos países, para justificar una etimología desde el punto de vista del significado. En nuestro caso, lo que sí debemos comparar son los topónimos de las distintas lenguas habladas en Costa Rica.

"Los datos geográficos": se trata de determinar si otros lugares llevan ese nombre y lo asocian con la presencia de nombres geográficos tales como agua o cualquier otro elemento.

De lo que se logró encontrar, en algunos casos la etimología de los nombres, el resultado es el siguiente:

\section{Análisis de Topónimos indígenas}

\subsection{Topónimos en lengua bribri}

Akum (1) Río

Àköm

De la raíz Àköm, nombre muy antiguo cuyo significado el informante desconoce pues pareciera que se perdió con los años. Según el informante, el río separa los pueblos de Puente y Salitre.

Amúo (2) Cerro

Amú

De la raíz ạmú 'pita'. Cerro pita.

Amurikal (2) Quebrada

De las raíces amú 'pita', ri 'agua' y kal 'árbol'. Quebrada donde hay pita y árboles. 
Araki (1) Cerro

Aláki

De la raíz aláki 'hembra'. Cerro hembra.

Ajcokichadick (1) Quebrada

Ajkö kicha di

Nombre que proviene de las raíces ajkö' 'canasta'; kicha 'cuerda', 'bejuco' y di ‘agua'. Río de bejuco de canasta.

Ambrí (1) Río

Ákbli

De las raíces ák 'piedra' y bli 'cauce'. Río de cauce con piedras o empedrado.

Ambruí (1) Cerro

Àkbli

De las raíces ák 'piedra' y bli ‘cauce'. Río de cauce con piedras o empedrado.

Beri (4) Cerro

Abë

De las raíces abë' 'golondrina', di 'agua, río'

Bikís (7) Sabana

De la raíz bikís 'bejuco grueso' 'ceibo'. Sabana del bejuco grueso o del ceibo.

Bita (2) (6) Cerro

Bitá

De la raíz bitá 'ardilla'. Cerro ardilla

Blorikal (1) Río

Blòdi

De las raíces Blò 'poró’ y ri ‘agua'. La última raíz, según el informante podría ser kéli cuyo significado es árbol Así el nombre del río sería Río del árbol poró.

Bukí (2) Quebrada

De la raíz bukë' 'sapo', 'rana'. Quebrada sapo o quebrada rana.

Bunú (2) Quebrada

De la raíz bùnu 'sapo grande'. Quebrada sapo grande.

Burí (2) Quebrada

De las raíz burí 'sapo'. Quebrada sapo.

Burú (2) Cerros

De la raíz burú 'sapito'. Cerros sapito. 
Chim Beta (1) Fila

De las raíces 'chim' 'mojado', 'húmedo', 'grande' y bata 'punta'

Fila mojada, húmeda y grande.

Burí (6) Quebrada

De la raíz bulë 'collares' Quebrada collares.

Chmuri (1) Quebrada

Chamù di

De las raíces chạunù 'musácea' y di 'agua'. Río del banano o río banano.

Chubugra (1) Río.

Chabö`kla

De las raíces chabö kala 'chapalear'. Río que va chapaleando.

Cuabri (1) Río

Uka'bli

De las raíces uka' 'caña brava' y bli 'cauce'. Cauce de la caña brava.

Datsi (2) Cerro

De las raíz datsi 'mastate'. Cerro mastate.

Deuí (2) Río

De la raíz dew"é 'pavo'. Quebrada del pavo.

Dibul (2) Cerro

De la raíz di 'agua' y bul 'brotar' 'desprender'. Cerro donde brota o se desprende el agua.

Ditsirí Suk (7) Sabana

De las raíces ditsi 'árbol' 'higuerón', ri 'agua' y sö 'k 'sabana'. Sabana donde hay agua y árboles de higuerón.

Dlora (1) Quebrada

Dolo'la

De las raíces dolo' 'pájaro’ y la' 'huevo, pichón'. Río del huevo del pájaro.

Guai (5) Quebrada

De la raíz bua'ë 'bien, bueno'. Quebrada buena.

Hurrí (1) Quebrada

De la raíz urrì 'oso hormiguero'. Quebrada oso hormiguero.

Jakjaka (7) Sabana

De la raíz jak 'piedra' y yaká 'abundancia'. Sabana abundante de piedras o pedregosa. 
Kaí (2) Cerro

Ka `ë

De la raíz ka`ë 'pava'. Cerro pava.

Kebé (1) Cerro

Kabèk

De la raíz kabék 'quetzal'. Cerro quetzal.

\section{Kuákua (1) Cerro}

Kua'kua

De la raíz kuá'kua 'mariposa'. Cerro mariposa.

Krugrá (6) (1) Quebrada nal o guineal

De las raíces kolöm ‘banano’ y kolö 'plantación'. Platanal o guineal. Quebrada plata-

\section{Kriyotan (2) Cerro}

Tsikiríyökbata

De la raíz Krítöbö ‘duende’. Lugar donde se concentran los duendes.

Nai (1) Cerro

Nại'

De la raíz nai 'danta'. Cerro danta.

Oka (7) Sabana

O'ka

De las raíces o' 'hacha' y aka 'punta' 'filo'. Sabana del filo del hacha.

Sebror (2) Quebrada y Sabana

Së'kbla

De las raíces së 'que recoge' y bror 'desechos', 'pedazos, basura'

Quebrada que recoge desechos de la montaña. Según el informante la palabra es una adaptación del bribri al español. En el caso de la sabana, la quebrada le da nombre a la sabana.

Simar (1) Quebrada

De la raíz tsímá 'platanillo'. Quebrada platanillo.

Sipar (1) Fila, río

De la raíz sipàr' 'bejuco cuya sabia es medicina'. Se usa para los dolores de estómago.

Sipardia (2) Quebrada

De la raíz sipàr' 'hoja de la planta que sirve para envolver muertos'.

Suidiñario (1) Quebrada

Tsawìnádiö 
De las raíces tsawì 'armadillo', ñá 'excremento' y diö 'líquido'

Quebrada el excremento líquido del armadillo.

\section{Surá (2) Río}

De la raíz sulá 'el artesano', 'el creador', 'el moldeador'. Se trata de una deidad que moldea al niño que nace para que sea artesano, agricultor o trabajador con las manos. Río del artesano

Tusí (1) Quebrada

De las raíces tu' 'ñame, tubérculo' y si 'seco'. Quebrada ñame o tubérculo seco.

Uíkuro (1) Cerro

Wi'kalo

De las raíces wî' kalo 'araña'. Cerro araña.

Uká (1) Cerro

Uka'

De la raíz uka' 'caña brava'. Cerro caña brava.

Yheri (1) Quebrada

Y’ëri

De las raíces y`ë 'sal’ y ri 'agua'. Quebrada de agua salada o quebrada salitre.

Yurá (2) Quebrada

De la raíz yular 'atol', 'refrescante', 'fermento', 'chicha'. Quebrada refrescante.

\subsection{Topónimos en lengua cabécar}

Cabagra (2) Poblado, fila y río

De las raíces Ka 'tierra', 'lugar' y baklö ‘algo que fue lo primero en existir'. El lugar que fue primero en existir.

Deri (7) Cerro

De la raíz deli 'carga'. Cerro carga.

Ditsirí (2) Quebrada

De la raíz ditsirí 'palmera'. Según el informante es un tipo de palmera con espinas que se utiliza en la comunidad para actos ceremoniales de concentración espiritual, cuando se hace ayuno. Los miembros del clan se ubican alrededor de la planta.

Declarí (2) Río

De las raíces dulë 'yurro', ka 'que sale del cerro parado' y ri 'agua'

Río que sale del cerro parado. 
Durega (2) Quebrada

De la raíz durega 'cerro parado o en posición vertical'. Quebrada del cerro parado.

Jakbarari (2) Quebrada de las piedras.

De las raíces jak 'piedra', bara 'dentro' y ri 'agua'. Quebrada o agua que corre dentro

Kitorí (2) Quebrada

De las raíces ki 'más', to 'lo que existe' y ri 'agua'. Según el informante es una alabanza a la abundancia algo así como '¿Qué dicha que existe algo más!'

Korí (2) Quebrada

De la raíz ko, planta con frutos amarillos cuando están maduros y ri 'agua'.

Koronono (2) Quebrada

De las raíces koró 'estampado', 'pintado de colores' y nono 'educado', 'fino', 'quieto', 'que no hace ruido'. Quebrada quieta o que no hace ruido.

Kuiye (2) Río

De la raíz kuiyé ‘ondulación'. Río con ondulaciones.

Murur Dibuk (7) Sabana

De las raíces mulurbi 'venado' y sök 'sabana'. Sabana del venado.

Pirgú Krikú (2) Quebrada

De la raíz pirgö 'planta aromática'.

Sarai (2) Río

De la raíz sara 'esparcido’ y i 'agua' Rio esparcido, que se mete, que pasa por las piedras.

Skrá (2) Río

De la raíz shkrá 'parte de las nubes, nube que baja, que corre veloz'. Quebrada que baja rápido, veloz, con mucho ruido, como tronando.

Tirgrá (2) Quebrada

De las raíces tir 'juguetona', 'vacilona', 'inquieta' y grá 'que se esconde y sale'. Quebrada juguetona.

Ururí (2) Quebrada

De la raíz urú ‘árbol de burío' y ri 'agua’. Quebrada del burío. Según el informante, este árbol cortado en trozos se usa en los actos ceremoniales; por lo tanto, para él sería Quebrada del urú o quebrada del que purifica. 


\subsection{Topónimos en lengua boruca}

Boruca (3) Poblado, quebrada

Brú"ncajc

De la raíz brún 'ceniza' y cajc 'zanja' 'cauce'. El poblado le da el nombre a la quebrada.

Bruncri (4) Quebrada

De la raíz brun 'ceniza' y crin 'tope'. El poblado le da el nombre a la quebrada.

Brurán (4) Sabana

De la raíz Brujrá"n 'zacate bajito'. Sabana con zacate bajito.

Canchén (3) Cerro y quebrada

De las raíces can 'piedra' y chén 'parte trasera'. Cerro que tiene piedra en la parte trasera. En el caso de la quebrada, el cerro le da el nombre.

Cansot (4) Poblado

De la raíz can 'piedra' y sot (raíz desconocida para la informante)

Castán (4) Fila

De las raíces cas 'zacate muy fino, como alfombra' y tan 'lomo', 'sabana', 'región', 'zona'. Fila, montaña, región o zona que tiene un zacate fino en el lomo.

Dutú (4) Alto

De la raíz dutuj 'pedazo de ñame'. Alto pedazo de ñame.

Gridum (4) Alto

De las raíces uri' 'zopilote' y dru"n 'punta'. La palabra en boruca es uidru"n. Alto o punta zopilote.

Cuasrán (4) Cerro

Cuasrán es un nombre propio.

Cuij Cuij (9) Sabana.

Cuij

De la raíz cuij 'gavilán'. Cerro gavilán.

Ruchén (4) Fila, río

De las raíces ru 'monte' y chén 'parte trasera'

Fila o montaña que tiene monte en la parte trasera. En el caso del río, la montaña le da el nombre.

Sankraua (4) Fila

Sancraua es un nombre propio. 
Shoabrá (4) (9) Río

De las raíces shoá' 'excremento' y brá 'mollejón'. La informante 4 desconoce sus significados; pero a la investigadora Carmen Rojas le informaron que hace unas décadas ese riachuelo funcionaba como retrete; de ahí su nombre.

Sinancra (4) Fila

De las raíces sin 'palmito' y rancra 'campo sembrado de'. Campo sembrado de palmito.

Yan (4) Quebrada

De la raíz yan 'beber'. Quebrada para beber o que se puede beber.

\subsection{Topónimos en lengua térraba}

Doboncragua (8) Poblado

Dobonde (8) Quebrada

Dobondecito (8) Quebrada

De las raíces dobó”n 'tigre' y dí ‘agua' Quebrada, poblado tigre.

\section{Algunas leyendas relacionadas con el topónimo o que justifican el nombre}

\section{Cerro Cuasrán}

La leyenda de Cuasrán se encuentra en el libro de Constenla (1986) Leyendas y tradiciones borucas. Se trata de un nativo que para no ser bautizado huyó y se escondió en la quebrada de Volcán. De noche salía a conversar con sus mujeres. Una de ellas, Ramona, tuvo un hijo de él que se llamó Sancrahua. Un día, muy de noche, en medio de un viento huracanado, Cuasrán se llevó a su hijo y lo puso en un cerro, al otro lado del río Grande; este cerro es muy alto, las personas no llegan hasta allí. Cuasrán le dio al hijo chanchos de monte muy buenos. En otra leyenda se habla de la fama que tenía Cuasrán de poseer mucho oro y de cómo un agente de policía, de apellido Johnson intentó escalar el cerro, agarrándose de bejucos; pero, aunque vio a un viejo que estaba bañándose en una poza, cuando lo llamó, este ni siquiera lo miró. Al señor Johnson le dio un miedo muy grande y disparó contra Cuasrán pero la escopeta no le funcionó y huyó del lugar dejando perdido todo lo que llevaba.

En la leyenda "La casa de Cuasrán", se narra el avistamiento que hizo un guanacasteco, de apellido Briceño, de la casa de Cuasrán. Desde lejos pudo apreciar niños, gallinas, chompipes y mujeres que salían a darles comida. Pero, al igual que el anterior, fracasó en su intento porque lo atrapó un aguacero con rayería que lo hizo regresar de nuevo cerro abajo. Allí ya no llovía. 


\section{Fila Sancrahua}

Es también un nombre propio y de acuerdo con la reseña anterior el nombre corresponde al del hijo de Cuasrán. En el libro de Constenla se recogen dos leyendas con su nombre: la primera, Sancrahua (primera versión), habla sobre su origen y la segunda, Sancrahua (segunda versión) se refiere a la costumbre del padre de Cuasrán de llegar con su hijo a casa de su mujer a beber chicha, comer y bailar. En el libro de Quesada Pacheco, Narraciones borucas, se recogen otras historias relacionadas con estos personajes: una es sobre los nietos de Cuasrán y los hijos de Sancrahua y otra sobre Ponciano Delgado y Cuasrán.

\section{Los animales comestibles del cerro}

Leyenda narrada por el indígena cabécar Silvano Villanueva Fernández. "Antiguamente, los animales de monte tenían dueño. El jefe de la tribu quería entregarles los animales del cerro a una reina y los de clima caliente a otra reina. Entonces lo tenía para estudiar cuál le tocaba. A las dos muchachas las mandaba a cocinar, a hacer café o cacao. Una era muy guapa pero muy despacio, muy lerda y la otra era más rápida. Entonces mandó la que era rápida para el clima caliente que va a ser la dueña de toda clase de animales que tiene el clima caliente, el clima caliente tiene un poquito más menos animales que el cerro y las más lerda la dejó en el cerro. De ahí viene que las dantas, y es cierto, es positivo eso, nosotros no vamos a matar esa danta así no más. Hay muchas personas que no comen animales; nosotros nos dividimos en razas, somos indios, pero hay unas razas que no comen eso y hay otras que sí. Entonces la danta es malo para comer; la danta tiene una enfermedad que puede ser muy malísima para las mujeres, para los hombres no, a los hombres les da tiempo todavía. Entonces la danta de clima caliente es más rápido para ponerle la enfermedad a la gente y la danta del cerro la gente la puede comer y puede que al tiempo le duela la cabeza, porque así era la reina muy lerda, muy despacio. Nosotros cumplimos eso porque el jefe dejó esos animales un poquito malos para comer porque si no fuera eso, la gente se pondría a gastarlos, a matarlos. Con eso, la gente los respetaba; el jefe dejó que los animales tuvieran enfermedades para que no los mataran a todos".

\section{Leyenda de la laguna de Carse}

Esta leyenda fur recopilada por Adolfo Constenla y aparece en el libro Nuestro Saber Oral. Voy a hablar un poquito nuevamente.

Un señor de antes trajo a una mujer de Talamanca, decía la gente, y la mujer trajo dos hijos. Hembra y varón. No, hembras solamente. Y, sus hijas estaban ya adolescentes y no hacían mas que jugar, no trabajaban, andaban solo riéndose: je je je. Y jugaban mucho e iban y venían, y tampoco se estaban en casa.

Y fue a donde sus jefes y habló con ellos:

¿_Por qué son así mis hijas?-les dijo.

_iAhi Porque sus hijas no son para ustedes, porque sus hijas están encantadas. Por ello, llévelas a donde hay lagunas, llévelas allá. Llévelas, allí les gustará y se quedarán. No lo piense, llévelas. Las niñas no son para usted-dijeron. 
Y así se fue, las llevó a una laguna y nada, las llevó subiendo de nuevo, a otra laguna, y nada. Las llevó subiendo, llevándolas.

- Carse es el nombre de la laguna- decía la gente-. La laguna de Carse es la de ellas.

Y las llevó, andando con ellas. Andando llegaban ya, iban cerca de su laguna y las niñas reían mucho, reían, reían, reían, reían y jugaban, reían y jugaban, reían y jugaban:

- ¿ Por qué será esto?- dijo a su hermano mayor.

-Porque ya están cerca de su laguna - le dijeron.

-Ajá.

Y fueron alrededor de la laguna, reían mucho, jugaban mucho y, entrando en la laguna, se sumergieron chas chas. Las metieron en la laguna. Se consumieron en la laguna. Se lanzaron dentro de ella.

Y, así, la gente no sabe cómo fue aquello, no lo sabe, no lo vio. Aquellas eran diablitas, porque eso, parecían, eran como diablitas.

\section{Informantes}

(1) Feliciano Elizondo Figueroa, informante del Departamento de Lingüística de la Escuela de Filología de la Universidad de Costa Rica.

(2) Severiano Fernández Torres. Departamento de Educación Indígena del Ministerio de Educación Pública.

(3) Celedina Maroto Leiva. Edad: 52 años. Nació en Boruca. Vive en Currés desde hace dos años. Maestra bilingüe de la Escuela de Currés.

(4) Marcelo Mayorga. Edad: 65 años. Nació en Cabagra y vive en ese mismo lugar.

(5) Margarita Obando. Edad: 41 años. Nació en Brisas y vive en ese mismo lugar.

(6) Aura Mayorga Rojas. Edad: 39 años. Nació y vive en San Rafael de Cabagra.

(7) Silvano Villanueva Fernández. Edad: 65 años. Nació y vive en Ujarrás, Buenos Aires.

(8) Adolfo Constenla. Investigador. Escuela de Filología, Lingüística y Literatura. Universidad de Costa Rica.

(9) Carmen Rojas. Investigadora. Escuela de Filología, Linguística y Literatura. Universidad de Costa Rica

\section{Conclusiones}

Al igual que los topónimos que se han estudiado en lengua española, los topónimos indígenas de las etnias que aún conservan hablantes reflejan la interacción del hombre con el 
medio. Del estudio realizado, es posible determinar algunas características de esta relación que se evidencian en la selección de raíces que constituyen los vocablos. Así, por ejemplo, el hablante para darle nombre al cerro, río, quebrada o poblado, toma, por una parte, los componentes del ambiente, lo que abunda en el lugar: piedras, animales, árboles, o bien, selecciona la característica más sobresaliente del accidente que se quiere denominar. De los componentes del ambiente se descatacan elementos de la flora, de la fauna, objetos o sustancias minerales.

Así, encontramos diversidad de plantas o animales tales como el cerro pita, el río del bejuco de canasta, la sabana del bejuco grueso o del ceibo, el río del banano, la sabana con agua e higuerones, el cerro caña brava, el cerro palmera, etc. Respecto de la fauna, se menciona el sexo como en el cerro hembra, el cerro golondrina, el cerro ardilla, la quebrada sapo, sapo grande, sapito, la quebrada pavo, el huevo o pinchón del pájaro, el oso hormiguero, el cerro pava, el cerro quetzal, la quebrada excremento líquido del armadillo, etc. Si se seleccionan las características del accidente como tal, se destaca un cerro mojado o húmedo, un río que chapalea, un cerro donde brota agua, el río que recoge los desechos de la montaña, la quebrada que tiene el agua salada,la quebrada que corre entre las piedras, la quebrada que no hace ruido, el río con ondulaciones, el río que se mete por entre las piedras, el cerro que tiene encima zacate muy fino o el cerro que tiene monte o piedras por detrás. Muy pocos nombres hacen referencia a la actitud que despierta el ambiente; por ejemplo, el cerro que no permite nada o como en el caso del nombre Cabagra, cuyo significado es el lugar que fue primero en existir; también el nombre de la quebrada Quitorí, que es una alabanza a la abundancia. Estos rasgos son comunes a los topónimos de las tres etnias que se han investigado: cabécar, bribri y boruca. Un detalle importante y común a estos grupos es el poco uso de nombres propios o comunes que se refieran específicamente a seres humanos. De los nombres bribris registrados solamente uno hace referencia a una deidad que moldea al niño para que sea artesano, agricultor o trabajador con las manos. Entre los borucas encontramos dos nombres que hacen referencia a seres humanos: el cerro Cuasrán y la fila Sankraua, nombres que corresponden, respectivamente, al de un padre y su hijo, según la leyenda.

\section{Bibliografía}

Aguilar, Carlos. 1965. Religión y magia entre los indios de Costa Rica de origen sureño. San José: Publicaciones de la Universidad de Costa Rica.

Bozzoli de Willie, María Eugenia. 1979. Localidades indígenas costarricenses. 2da. Edición. San José: Editorial Universitaria Centroamericana.

1973. Indígenas actuales en Costa Rica. (Conferencia dictada en 1973). Mimiógrafo.

Chang, Guisselle y Ximena del Río. 1998. Nuestro saber oral. San José: Serie Culturas Populares Centroamericanas.

Constenla, Adolfo y Espíritu Santo Maroto. 1986. Leyendas y tradiciones borucas. 2da. Edición. San José: Editorial de la Universidad de Costa Rica. 
Corominas, Joan. 1972. "Toponomástica Cuyana”. En Tópica Hespérica. Madrid: Editorial Gredos.

Ley No. 5251. Ley de creación de la comisión nacional de asuntos indígenas. CONAI. 1973.

Ley No. 6172. Ley indígena. 1979.

Quesada Pacheco, Miguel A. Narraciones borucas. 1996. San José: Editorial de la Universidad de Costa Rica.

Rojas, Carmen. 1988. "Descripción y análisis de la fiesta de los diablitos de Boruca". Estudios de lingüística chibcha. Serie anual. Tomo Vll. San José: Editorial de la Universidad de Costa Rica. 


\section{ANEXO}

\section{Topónimos indígenas pendientes}

\begin{tabular}{|c|c|c|c|}
\hline Bacrác & Quebrada & Genera & 534329 \\
\hline Bapori Sikri & Quebrada & Buenos Aires & 540354 \\
\hline Barú & Playa & Dominical & 447357 \\
\hline Barú & Río & Dominical & 479358 \\
\hline Bekis & Sabana & Buenos Aires & 540356 \\
\hline Brusmalis & Quebrada & Coto Brus & 567311 \\
\hline Burú & Cerros & Pittier & 592330 \\
\hline Cabagra & Fila & Pittier & 549342 \\
\hline Cabagra & Poblado & Cabagra & 550334 \\
\hline Cabagra & Río & Cabagra & 549343 \\
\hline Caracucha & Sabana & Cabagra & 552329 \\
\hline Cantú & Poblado & Coto Brus & 547320 \\
\hline Caringo & Quebrada & Coronado & 493345 \\
\hline Changual & Estero & Dominical & 490347 \\
\hline Changual & Quebrada & General & 527333 \\
\hline Changual & Alto & General & 525333 \\
\hline Chánguena & Poblado & Coto Brus & 551321 \\
\hline Chánguena & Río & Coto Brus & 543324 \\
\hline Chiká & Quebrada & Pittier & 588330 \\
\hline Chobá & Río & Unión & 580318 \\
\hline Coeching & Quebrada & Chánguena & 531322 \\
\hline Cotón & Río & Unión & 580322 \\
\hline Cotón & Fila & Unión & 576322 \\
\hline Cuachí & Quebrada & Chánguena & 531324 \\
\hline Cuán & Río & Cabagra & 549335 \\
\hline Damatra & Quebrada & Cabagra & 560336 \\
\hline Degro & Cerro & Llorona & 518280 \\
\hline Deri & Cerro & Durica & 529366 \\
\hline Dibreki & Quebrada & Unión & 598327 \\
\hline Dudú & Cerro & Kamuk & 565355 \\
\hline Dufú & Alto & Chánguena & 542326 \\
\hline Fiuri & Quebrada & Coto Brus & 550324 \\
\hline Gridrum & Alto & General & 538330 \\
\hline Grunchen & Fila & General & 529330 \\
\hline Guágara & Quebrada & Repunta & 493352 \\
\hline Guasjiba & Quebrada & General & 537330 \\
\hline Irkibí & Cerro & Unión & 593325 \\
\hline Kivú & Cerro & Coto Brus & 547316 \\
\hline Kirdigua & Quebrada & Cabagra & 550330 \\
\hline Kriyotan & Cerro & Kamuk & 54348 \\
\hline
\end{tabular}




Krugrá
Kurlo
Kurú
Kutsí
Miska
Ñeque
Ñeque
Nin
Piro
Piro
Rimbaya
Rujbó
Sagrí
Saré
Shoabrá
Shoseragua
Siak
Singri
Skebaco
(Shebaco) Stak
Surí
Sutú
Térraba
Siba
Tolé
Tonduz
Turubo
Tusí
Urubuk
Utsi
Yan
Yursuk

Quebrada

Río

Cerro

Cerro

Quebrada

Quebrada

Playa

Cerro

Río

Playa

Río

Quebrada

Quebrada

Río

Río

Quebrada

Río

Río

Quebrada

Río

Quebrada

Quebrada

Río

Quebrada

Quebrada

Cerro

Río

Quebrada

Cerro

Cerro

Quebrada

Quebrada
Cabagra

Kamuk

Cabagra

Cabagra

General

Golfo Dulce

Golfo Dulce

Burica

Carate

Carate

General

Chánguena

Coto Brus

Unión

Chánguena

Chánguena

Unión

Cabagra

General

Coto Brus

Pittier

Unión

Coronado

General

Cabagra

Cabagra

Pittier

Coto Brus

Kamuk

Kamuk

Chánguena

Buenos Aires
551334

550347

570339

566344

531337

536279

537280

585231

536264

536261

540329

535327

556321

582317

544320

538326

580321

565335

524343

572323

587330

599325

504332

538336

551329

573333

576336

573320

557351

561356

587325

540364 